\title{
Cocriação e Design Thinking: uma Experiência de Inovação no Serviço Público em um Município Brasileiro
}

\section{Co-creation and Design Thinking: an Experience of Innovation in Public Service in a Brazilian Municipality}

\author{
Eduarda Montibeller Schuch \\ Universidade do Estado de Santa Catarina - UDESC - Brasil \\ dumontibeller@gmail.com \\ ORCID: 0000-0001-6075-6107 \\ Micheline Gaia Hoffmann \\ Universidade do Estado de Santa Catarina - UDESC - Brasil \\ michelinegaia@gmail.com \\ ORCID: 0000-0001-8516-2137
}

Recebido: 11 Janeiro 2021
Revisado: 04 Abril 2021
Aceito: 01 Maio 2021

\begin{abstract}
Resumo
Objetivo: Este artigo tem o objetivo de analisar uma experiência de cocriação para a inovação do Serviço de Liberação para Realização de Eventos em Espaço Público, realizada na Prefeitura Municipal de Balneário Camboriú. Metodologia: A pesquisa, de natureza qualitativa, consiste num estudo de caso que fez uso de levantamento documental, observação participante e entrevistas para a coleta de dados e da análise de conteúdo para a investigação. Assumiu as categorias de análise: origem e objetivo da experiência e sua interface com a inovação; características do processo; atores participantes; abordagem; ferramentas adotadas; indutores e barreiras; tipologia / caracterização da inovação gerada; e resultados atingidos. Resultados: A pesquisa revela a consecução de um processo iterativo de colaboração em que servidores da prefeitura resolveram um problema em conjunto com usuários do serviço. Contribuições: 0 artigo apresenta evidências empíricas de um processo de cocriação que resulta em uma solução com características inovadoras, suprindo lacunas teóricas e gerenciais apontadas em trabalhos nacionais e internacionais recentes.
\end{abstract}

Palavras-chave: Inovação; serviço público; cocriação; design thinking.

Abstract

Purpose: This article aims to analyze a co-creation experience for the innovation of the Liberation Service for Events in Public Space, held at the Municipality of Balneário Camboriú. Methodology: The research, under a qualitative nature, consists of a case study that made use of documentary survey, participant observation and interviews for data collection and content analysis for examination. It assumed as categories of analysis: origin and objective of the experience and its interface with innovation; process characteristics; participating actors; approach; adopted tools; inductors and barriers; typology / characterization of the innovation generated; and results achieved. Results: The research reveals the achievement of an iterative process of collaboration in which city officials solved a problem along with users of the service. Contributions: The article presents empirical evidence of a co-creation process that results in a solution with innovative characteristics, filling theoretical and managerial gaps pointed out in recent national and international studies.

Keywords: Innovation; public service; co-creation; design thinking.

\section{Introdução}

O setor público enfrenta um número crescente de problemas difíceis de resolver, uma vez que as soluções devem atender a diferentes requisitos. São os chamados wicked problems (Ansell \& Torfing, 2014). É o caso, por exemplo, do alto índice de crime nas ruas, que pode ser explicado por não haver policiamento suficiente, pelo alto número de criminosos, por leis inadequadas, pela privação cultural, pelo excesso de armas, entre outros motivos que, no seu conjunto, tornam o problema de difícil solução, dada a complexidade envolvida (Rittel e Webber, 1973). Para enfrentar esse tipo de problema, torna-se necessário formular novas respostas. Nesse contexto, a inovação surge como uma maneira de melhorar o desempenho do governo e permitir que a administração pública seja mais responsiva ao cidadão. 
Quando se assume que o tema "inovação no setor público" transcende a perspectiva schumpeteriana, baseada numa lógica de manufatura (Schumpeter, 1982), para incorporar uma abordagem de serviços (Osborne, 2013), constata-se que o valor a ser entregue deve ser cocriado com o usuário (Trischler \& Scott, 2016). A capacidade de cocriação passa a ser uma condição para se criar inovações em serviços públicos que realmente atendam às necessidades do cidadão (Voorberg, Bekkers \& Tummers, 2015). Por cocriação, Voorberg, Bekkers e Tummers (2015) assumem desde o envolvimento dos cidadãos com a iniciativa de formular o serviço (coiniciador), até o seu envolvimento com a formulação do conteúdo e entrega (co-designer).

A crescente demanda para considerar usuários como cocriadores de valor nos sistemas de serviços públicos traz uma série de desafios à administração pública, que precisa passar a atuar como um sistema aberto e colaborativo. Em decorrência disso, novas metodologias tornam-se necessárias para que usuários possam cocriar a experiência que desejam ter (Trischler \& Scott, 2016).

A abordagem do design thinking emerge nesse contexto como um aparato metodológico e ferramental para possibilitar o envolvimento de vários atores no design e na implementação de serviços públicos (Ansell \& Torfing, 2014). Com base nisso, governos ao redor do mundo têm buscado nesse referencial, amparo para implementar processos de cocriação (Ansell \& Torfing, 2014). No Brasil, Santos e Hoffmann (2015) desenvolveram uma pesquisa que teve o objetivo de propor uma metodologia para o Design e a Implementação de Serviços Públicos efetivos no contexto de um projeto no município de Florianópolis, apoiado nos pressupostos conceituais do Design de Serviços e do Gerenciamento de Projetos. Ainda, Cavalcante (2019) organizou uma coletânea que contribuiu para o debate da cultura de inovação no Brasil, uma vez que apresenta e discute casos que implementam métodos e abordagens inovadoras de gestão e políticas públicas em distintos setores e esferas de governo.

Contudo, Voorberg et al. (2015) chamam a atenção para o pouco conhecimento empírico existente sobre cocriação e para a escassez de evidências que permitam posicioná-lo como estratégia relevante. Ainda, Voorberg et al. (2015) levantam questões sobre, por exemplo, quais os objetivos da cocriação com cidadãos, que fatores influenciam o processo e quais resultados se pode esperar. Apontam, ainda, para a escassez de trabalhos que olhem para o cidadão como coiniciador ou codesigner, denunciando o foco predominante no seu papel apenas como coimplementador de serviços públicos concebidos pelo estado.

Trischler e Scott (2016) adicionam a esses questionamentos a escassez de estudos que pesquisem métodos de envolvimento de usuários no design de serviços em diferentes contextos do serviço público. De forma similar, Cavalcante (2019) destaca que apesar do avanço que se tem visto no Brasil quanto ao desenvolvimento de materiais e à capacitação de servidores para a disseminação do design thinking no governo, é preciso compreender de forma mais aprofundada seus princípios, para que a abordagem possa ser impulsionada e, de fato, incorporada. Para Cavalcante (2019), ainda carecemos de conhecimento estruturado sobre essa abordagem e como ela se enquadra nas práticas atuais das organizações públicas.

Uma experiência de cocriação baseada nos princípios e ferramentas do design thinking para a inovação do Serviço de Liberação para Realização de Eventos em Espaço Público (SLREEP) foi implementada pela Prefeitura Municipal de Balneário Camboriú (PMBC). Isso aconteceu porque o serviço prestado apresentava problemas relacionados ao tempo de espera e falta de transparência, o que gerava inúmeras reclamações por parte dos cidadãos e dificuldades para os servidores da prefeitura desempenharem a sua função no processo (Schuch, Souza \& Salm, 2019).

Nesse contexto, o presente trabalho tem o objetivo de analisar a experiência de cocriação para a inovação do SLREEP realizada na PMBC. Considerando as lacunas de conhecimento apresentadas anteriormente (Voorberg et al., 2015; Trischler \& Scott, 2016; Cavalcante, 2019), o estudo enfoca a origem e objetivo da experiência e sua interface com a inovação, características do processo, atores participantes, abordagem, ferramentas adotadas, fatores indutores e barreiras, tipologia / caracterização da inovação gerada e resultados atingidos. Além disso, a pesquisa está delimitada de forma a permitir olhar para o usuário como coiniciador e co-designer, nos termos propostos por Voorberg et al. (2015).

Pretende-se, dessa forma, contribuir com a literatura do campo, considerando a escassez de estudos anteriormente apontada, sobretudo no que tange o estudo de experiências realizadas no Brasil. Além disso, espera-se contribuir com a prática da administração pública, desvendando facetas de um tema ainda pouco dominado por gestores, apesar da sua franca difusão no contexto gerencial nos últimos anos.

\section{Fundamentação Teórica}

Com o objetivo de fundamentar esta pesquisa é relevante abordar os temas referentes a (2.1) inovação 
no setor público: aspectos conceituais e tipologias e (2.2) Design Thinking e cocriação para inovação de serviços públicos. Estes são os principais temas contidos no objetivo deste artigo; portanto, para realizá lo, é necessário que eles sejam apresentados neste referencial teórico.

\subsection{Inovação no setor público: aspectos conceituais e tipologias}

A inovação, quando planejada, parte de um objetivo, que busca demonstrar a intenção de determinada tarefa, ou seja, aonde se quer chegar. Com base em uma revisão sistemática da literatura, De Vries, Bekkers e Tummers (2016) explicam que a inovação no setor público, de um modo geral, tem três objetivos: (i) melhorar a eficiência em ações internas, (ii) aprimorar serviços e soluções com foco nos cidadãos e (iii) promover inovação em outros setores da organização.

O objetivo da inovação que busca melhorar a eficiência em ações internas de uma instituição diz respeito ao fato de que, quando planejada, visa alcançar um rendimento melhor em suas ações internas. Já a inovação que possui o objetivo de aprimorar serviços e soluções, sejam para o cidadão, cliente ou para negócios, olha para fora da instituição. Por fim, a inovação que tem o objetivo de promover inovação em outros setores, considera mudanças mais abrangentes, e não em ações específicas, pois considera o todo de um determinado setor (De Vries et al., 2016).

Diferentes objetivos tendem a conduzir diferentes tipos de inovação. A Organisation for Economic Co-operation and Development [OECD] (2005) apresenta quatro tipologias de inovação, sendo elas: (i) inovação em produto ou serviço, (ii) em processo, (iii) em marketing e (iv) organizacional. A inovação em produto refere-se a um bem ou serviço novo ou melhorado consideravelmente, entretanto, leva em conta as suas características ou finalidades. Já a inovação em processo diz respeito a um procedimento de produção ou distribuição, podendo ser um procedimento novo ou aperfeiçoado. Quando uma inovação ocorre em um procedimento de marketing, sendo que essa inovação possui uma modificação considerável, classifica-se como inovação em marketing. Por fim, nas situações de mudanças no procedimento organizacional, sendo nos negócios de uma empresa, nas rotinas de trabalho ou até mesmos relacionados com o ambiente externo, caracteriza-se como inovação organizacional.

Com foco nas especificidades do setor público, a OECD, por meio do Observatory for Public Sector Innovation [OPSI] (2018), apresenta outras tipologias. O primeiro tipo é a inovação orientada ao aperfeiçoamento, sendo pautada pela questão: como podemos fazer melhor? 0 segundo tipo é a inovação orientada à missão, que é movida por uma ambição de se atingir determinada meta. A terceira é a inovação adaptativa, que emerge para responder a um fato que desequilibra a resposta vigente em relação ao que é esperado. Por fim, a inovação antecipatória, onde há espaço para engajamento com a incerteza inerente ao questionamento: como as possibilidades emergentes poderiam mudar fundamentalmente o que determinada situação poderia vir a ser?

A tipologia do OPSI (2018) incorpora a noção de que a inovação pode ter diferentes graus de intensidade quanto à novidade, reconhecendo que pode navegar desde uma intensidade incremental, até transformações de ruptura. Ela não desmerece o valor do que chama de inovação orientada ao aperfeiçoamento, mas propõe que gestores interessados em promover a inovação de forma deliberada, considerem a gestão de portfólio, incorporando uma variedade de iniciativas com diferentes potencialidades quanto ao impacto.

Na perspectiva do valor contido nas iniciativas com menor grau de sofisticação, tem surgido o conceito de inovação frugal. Segundo Koerich e Cancellier (2019), esse tipo de inovação promove o (re)design de produtos e serviços por meio de improvisação criativa. Ele está associado à introdução de algo novo ou diferente com o uso de poucos recursos, criando proposições de valor atraente para o público-alvo a partir do foco nas funcionalidades essenciais.

Hartley (2005) também apresenta outra classificação. Esta destaca as seguintes tipologias de inovação no setor público: (i) inovação de posicionamento, (ii) inovação estratégica, (iii) inovação em governança e (iv) inovação retórica. A primeira refere-se a novos contextos ou usuários. A segunda diz respeito a novas metas ou propósitos da organização. Já a terceira refere-se a situações em que há mudanças envolvendo novas formas de cidadania, engajamento e instituições democráticas, que têm como conceito-chave o valor público, e visa alcançar o interesse público. Quando há novas linguagens e novos conceitos que são introduzidos e aceitos pela sociedade, caracteriza-se como inovação retórica.

A inovação em governança, descrita por Hartley (2005), traz à tona o caráter colaborativo da inovação no setor público. De acordo com esse conceito, a inovação deixa de ser resultado de uma ação dos órgãos governamentais, para se tornar um desafio que exige a presença de governança colaborativa.

De acordo com essa lógica, diferentes atores fazem parte do processo de inovação, abrangendo o setor público, privado, organizações do terceiro setor, a sociedade e os cidadãos. Ansell e Torfing 
(2014) fazem uma análise de como o paradigma assumido como fundamento interfere no que se compreende por inovação no setor público. Demonstram que, ao se migrar dos pressupostos da Nova Gestão Pública para a Nova Governança Pública, é preciso abandonar a noção de que a inovação é um fenômeno que depende da capacidade empreendedora dos servidores públicos para reconhecer que ela é um processo colaborativo que transcende as fronteiras institucionais. Nessa perspectiva, ela deixa de ser um fenômeno restrito a uma abordagem top down, para incorporar possibilidades multidirecionais.

Cavalcante e Camões (2017) apresentam três abordagens: (i) top down, (ii) horizontal e (iii) bottom up. A abordagem top down ocorre quando a inovação é desenvolvida e implementada em decorrência do engajamento de pessoas do alto escalão da organização. Já a abordagem horizontal refere-se à inovação que está sendo desenvolvida e implementada por meio de um processo de cocriação, em que participam funcionários de várias hierarquias da organização, baixo e médio escalão com seus líderes. A abordagem bottom up, a seu turno, diz respeito à inovação que, quando desenvolvida e implementada, é empreendida de baixo para cima, ou seja, por equipes que compõem a hierarquia mais baixa da organização e sem o envolvimento de seus líderes.

Os pressupostos assumidos para se compreender o fenômeno, bem como a abordagem adotada, interferem na forma como se conceberá o processo. A OECD (2017) descreve o processo partindo da identificação do problema, fase em que é necessário entender onde e como uma resposta inovadora é necessária. Após, inicia-se a geração de ideias para responder ao problema elencado na etapa anterior. Selecionadas as principais ideias, é necessário desenvolver as propostas, ou seja, transformar as ideias em casos de negócios para que possam ser avaliados e adotados. Em seguida, é o momento de implementar os projetos e fazer a inovação acontecer. É importante avaliar os projetos para entender se a iniciativa inovadora forneceu o que era necessário para a organização. Por fim, é preciso iniciar a etapa da difusão das lições para usar o que foi aprendido para informar outros e futuros projetos e avaliar como a inovação pode ser aplicada de outras maneiras.

\subsection{Design Thinking e cocriação para inovação de serviços públicos}

Compreendendo a inovação no setor público sob a perspectiva da governança colaborativa, Ansell e Torfing (2014) propõem a incorporação dos princípios do design thinking ao processo. Nesse sentido, Cavalcante (2019) propõe três princípios: (i) foco no ser humano (as necessidades e expectativas de quem vivencia o problema é central), (ii) cocriação de soluções para gerar possibilidades (o viés da construção de entendimento e soluções é transdisciplinar, envolvendo a participação de múltiplos atores) e, por fim, (iii) experimentação (disposição para a testagem sistemática de protótipos, de forma que a captura de feedback proporcione aprendizagem e permita o aperfeiçoamento do conceito inicial, aproximando-o cada vez mais da necessidade do usuário).

0 conceito de cocriação com usuários aparece nesse contexto associado a uma condição necessária para se criar serviços públicos inovadores, que realmente atendam às necessidades do cidadão. Voorberg et al. (2015) constatam que existe uma confusão conceitual no uso dos conceitos de cocriação e coprodução, que frequentemente são utilizados de forma intercambiável. Em suas considerações finais, os autores optam por associar o termo cocriação ao envolvimento dos cidadãos aos níveis de coiniciação (quando o cidadão toma parte na iniciativa de formular serviços específicos) e co-design (quando seu envolvimento envolve o conteúdo e o processo de entrega do serviço), associando a coprodução ao nível da coimplementação (quando o cidadão é envolvido apenas na entrega de um serviço concebido pelo governo). Esta definição encontra controvérsias na literatura de coprodução (Brandsen \& Honingh, 2015). Entretanto, como essa discussão foge do propósito deste trabalho, ela não será desenvolvida. Assume-se, aqui, a opção proposta por Voorberg et al. (2015).

Nessa perspectiva, tem-se um processo de inovação iterativo e participativo, em que, por meio da cocriação, procura-se ganhar mais efetividade, eficiência, satisfação do usuário, crescente engajamento do cidadão, dentre outros objetivos (Voorberg et al., 2015). Ao discutir resultados de processos conduzidos nessas bases, Voorberg et al. (2015) destacam o atingimento desses objetivos e apontam ainda o fortalecimento da coesão social e a democratização dos serviços públicos. De Vries et al. (2016) apresentam resultados similares: eficiência em ações internas (políticas e iniciativas); aprimoramento de serviços e soluções para cidadãos e negócios; e promoção da inovação em outros setores. Há, portanto, uma convergência entre objetivos firmados e resultados alcançados.

Verifica-se também que os resultados apontados na literatura com foco na cocriação com o cidadão dialoga com aqueles elencados para o constructo da participação social: possibilita novas formas de governança, capazes de enfrentar situações complexas; auxilia a restabelecer os laços de confiança entre governo e cidadãos; confere maior legitimidade às decisões públicas; melhora a qualidade da tomada de decisão, a partir do conhecimento e experiência dos cidadãos; traz maior eficácia, agilidade e economia às ações públicas; contribui para a transparência e novas formas de 
accountability; gera aprendizado e habilita as pessoas para exercerem sua cidadania; e, propicia soluções inovadoras e novas formas de entrega dos serviços públicos (Struecker \& Hoffmann, 2017).

Entretanto, a natureza burocrática predominante nas organizações públicas torna a implementação de processos pautados pelos princípios do design um desafio, de forma que os objetivos e resultados descritos anteriormente não acontecem sem enfrentar barreiras. Por isso, vários autores discutem quais são as características organizacionais que facilitam ou dificultam a implementação de experiências e processos com as características anteriormente descritas.

Segundo a European Comission (2013), os indutores para a inovação podem ser divididos em dois grupos: internos e externos. Os indutores internos são aqueles que estão atrelados à organização, sendo a cultura organizacional, a liderança organizacional, gestão de recursos humanos, e a comunicação interna e externa, considerando os diversos atores envolvidos em um processo de inovação. Outrossim, os indutores externos, referentes a atores e situações que estão fora da organização são estes: o quadro legislativo conveniente, as necessidades públicas e as expectativas dos cidadãos, o efêmero surgimento de novas tecnologias e, por último, a presença de estímulo político pelos tomadores de decisão. Além disso, a cooperação entre os atores envolvidos pode ser caracterizada como um indutor importante (Demircioglu \& Audretsch, 2017).

Voorberg et al. (2015) discutem fatores que influenciam especificamente a capacidade de cocriação, subdividindo a análise em duas perspectivas: a da organização e a do cidadão. Do ponto de vista da organização pública, destaca a compatibilidade entre ela e participação cidadã, a cultura de aversão ao risco e a presença de incentivos claros para a cocriação, numa situação de ganha-ganha. Do ponto de vista do cidadão, destaca as características do cidadão chamado a cocriar, o sentimento de pertencimento, a presença de capital social e a aversão ao risco. Assim, os fatores apontados por Voorberg et al. (2015) podem assumir característica de indutor ou barreira.

Para auxiliar no processo de inovação por meio do design, várias ferramentas e métodos podem ser utilizados para promover a colaboração entre os atores. Dentre eles, estão a persona, o mapa de empatia, o brainstorming e a prototipagem de serviço. O mapa de empatia, utilizado para a construção de personas de usuários, possui o intuito de entender a necessidade do usuário do serviço (Trischler \& Scott, 2016). As personas construídas auxiliam a compreender informações de pessoas semelhantes, que solicitam o serviço, para criar uma única persona que representa o grupo. Além disso, esse método ajuda quem está pensando o serviço a entender as reais necessidades dos usuários (Trischler \& Scott, 2016).

O brainstorming se caracteriza como uma técnica usada para gerar soluções diversas e oportunidades de forma ágil e rápida (Design Council, 2015). Nesse sentido, tal método ajuda na identificação das ideias mais relevantes para serem levadas adiante como parte do processo de inovação. Ademais, tem como objetivo criar um entendimento compartilhado, entre os participantes, de ideias que possuem potenciais.

A prototipagem de serviço, segundo Stickdorn e Schneider (2014), é um método para testar novas ideias de serviços. Dessa forma, uma ideia é transformada em um protótipo para ser testado antes de ser implementado. Os protótipos servem para demonstrar como será esse serviço e permitir que seja testado e refinado esse protótipo com os usuários. Esse método tem o objetivo de projetar e testar os serviços, verificar se todas as partes do serviço atendem às necessidades dos usuários e como elas podem ser aprimoradas.

Essas são algumas de inúmeras ferramentas associadas ao design thinking como abordagem para a solução de problemas e estímulo à inovação com foco no usuário. Embora haja uma proliferação de toolkits descrevendo-as e expondo como utilizá-las, faltam estudos que contribuam para uma compreensão mais profunda de como elas podem ser implementadas na administração pública (Trischler \& Scott, 2016; Cavalcante, 2019). Nesse sentido, as ferramentas constituem uma das categorias de análise que compuseram a presente pesquisa, demonstrado na seção a seguir.

\section{Procedimentos Metodológicos}

Esta pesquisa se caracteriza como um estudo de caso de natureza qualitativa e descritiva (Vergara, 2011), posto que tem como objetivo apresentar as características de determinado fenômeno. 0 fenômeno analisado é uma experiência de cocriação baseada nos princípios do design thinking para a inovação do SLREEP realizada na Prefeitura Municipal de Balneário Camboriú (PMBC).

Os instrumentos de coleta de dados mesclaram levantamento documental, entrevista e observação participante. Por meio da pesquisa documental, foram levantados os eventos aprovados em 2018 na PMBC, antes da alteração do processo, e após a alteração, no ano de 2019, bem como regulamentos e decretos vigentes sobre a matéria. As entrevistas foram realizadas com base em um roteiro estruturado e dois grupos de sujeitos a serem entrevistados: Grupo A e Grupo B.

Fazem parte do Grupo A os participantes da oficina de cocriação na PMBC. Nesse grupo foram 
entrevistadas oito pessoas, sendo:

- Três representantes da PMBC envolvidos no serviço, um servidor da Secretaria de Meio Ambiente (E1), um da Secretaria de Planejamento (E2) e um da Secretaria de Turismo (E3);

- Três usuários representativos do perfil de usuário do serviço, um cidadão (E4), uma empresa privada (E5) e uma entidade do sistema S (E6);

- Dois representantes de universidades (E7 e E8) que auxiliaram na condução da oficina, alunos do curso de Administração Pública da Universidade do Estado de Santa Catarina (UDESC).

Do Grupo B faz parte a pessoa da PMBC que participou diretamente da implementação da solução criada na oficina de cocriação, servidor da Secretaria de Planejamento (E9).

A observação participante foi conduzida por uma pesquisadora da UDESC que atuou como facilitadora da oficina e participou do processo como observadora ativa, com o objetivo de compreender a dinâmica do grupo durante as atividades e interações propostas e, dessa forma, ir além das respostas individuais às questões formuladas nas entrevistas.

Para proporcionar uma compreensão mais profunda do fenômeno em estudo, procurou-se triangular os dados por meio do uso de diferentes instrumentos de coleta, fontes de dados e sujeitos de pesquisa (Zappellini \& Feuerschütte, 2015). Para a análise de dados, foi utilizada a técnica de análise de conteúdo, de acordo com Bardin (2006). Inicialmente, foi realizada a leitura dos dados coletados no levantamento documental, nas anotações de campo, e nas entrevistas, que foram integralmente transcritas. Na sequência, a partir de um esforço de codificação, o conteúdo foi analisado à luz das categorias identificadas na literatura. $\mathrm{O}$ modelo de análise assumido como referência para o desenvolvimento da pesquisa foi composto por categorias fundamentadas em Trischler e Scott (2016), Voorberg et al. (2015) e Cavalcante (2019). São elas: origem e objetivo da experiência e sua interface com a inovação, características do processo, atores participantes, abordagem, ferramentas adotadas, fatores indutores e barreiras, tipologia/caracterização da inovação gerada e, finalmente, resultados atingidos. A próxima seção discute os resultados da pesquisa com base nessas categorias analíticas.

\section{Discussão e Análise dos Resultados}

A inovação que constitui o objeto de análise do presente estudo foi uma experiência de cocriação aplicada sobre o SLREEP da PMBC. A experiência envolveu vários atores de diferentes áreas que, com base nos princípios do design thinking e fazendo uso de ferramentas, redesenharam o serviço por meio de um processo iterativo e colaborativo.

A origem da inovação foram problemas no SLREEP, caracterizados por meio da pesquisa documental. O SLREEP era regulamentado pelo Decreto $n^{\circ} 7.569$ de 2014 e seguia determinações de um Termo de Ajustamento de Conduta de 2007, firmado pelo Ministério Público de Santa Catarina com o Comando do Batalhão da Polícia Militar, Delegado Regional de Polícia, Secretário da Fazenda, Secretário de Planejamento Urbano, Secretário do Meio Ambiente, Secretário da Saúde e Comando do Corpo de Bombeiros.

O SLREEP iniciava quando o cidadão entrava com o pedido no Protocolo Geral da prefeitura, que o encaminhava para o Departamento de Fiscalização da Secretaria de Planejamento (DEFO). 0 DEFO enviava o pedido para a Secretaria de Meio Ambiente, Secretaria de Segurança Pública, Fundo Municipal de Trânsito e Secretaria de Turismo por e-mail, para que essas secretarias analisassem com base nas competências de cada área. Após a análise das secretarias, as mesmas deferiam ou indeferiam o pedido por meio de uma declaração escrita e assinada pelo responsável da área, e encaminhavam para o DEFO. O DEFO comunicava ao cidadão requerente quando alguma secretaria indeferia, para explicar os motivos do indeferimento. Quando todas defeririam, o DEFO emitia uma declaração final e entregava para o cidadão requerente.

Contudo, de acordo com o E2, o serviço em questão apresentava problemas relacionados à falta de informação, por parte do usuário, no momento em que ingressava com seu processo na PMBC. Essa falta de informação culminava em retrabalho para as Secretarias envolvidas e em perda de tempo para os usuários, que frequentemente precisavam retornar à Prefeitura e adicionar informações faltantes solicitadas pelos servidores, reitera o E2. Frente a esse cenário, segundo o E1, E2, E3, E4, E5 e E6, vários usuários estavam insatisfeitos com o serviço, uma vez que não dispunham das informações e documentações necessárias para ter o seu evento aprovado. Observou-se insatisfação também por parte dos servidores públicos, pois os processos se estendiam por um tempo desnecessário, interferindo negativamente na sua rotina de trabalho. A situação que originou a iniciativa caracterizava-se, portanto, pelo insuficiente atendimento à necessidade do usuário, por um lado, e pela ineficiência dos processos para os servidores da PMBC, por outro.

Segundo o E1, E2 e E3, com vistas a sanar o problema, foram realizadas duas reuniões internas, 
mas não se obteve êxito. Frente a esse cenário, o E2 destaca que uma servidora comissionada da Secretaria de Meio Ambiente, somado a servidores de nível de rua da Secretaria de Planejamento, resolveram partir para outra abordagem. A estratégia foi convidar para participar todos os servidores da prefeitura envolvidos no processo, cidadãos que apresentavam reclamações sobre o serviço e a universidade, para auxiliar no método a ser adotado, destaca o E1.

O objetivo da experiência foi discutir e pensar soluções inovadoras para o serviço de forma que a solução contemplasse as dores dos diferentes atores envolvidos. Tal objetivo alinha-se ao propósito estabelecido na literatura para o uso do design thinking como método para impulsionar a inovação em processos de design e redesign de serviços públicos (Cavalcante, 2019; Lochhead, 2017; Ansell \& Torfing, 2014).

A análise das entrevistas dos diferentes grupos de atores revelam percepções distintas entre eles quanto aos objetivos. Para E1, E2 e E3, esperava-se melhorar o serviço de tal forma a aumentar a eficiência nos processos internos. No caso específico, o E1, E2, E7 e E8 destacam a expectativa de levar para o poder público experiências capazes de gerar soluções inovadoras por meio do envolvimento do usuário. Do ponto de vista do E4, E5 e E6, o objetivo era receber melhor o serviço.

Assim, os objetivos associados à experiência remetem não apenas à busca de efetividade na prestação de serviços públicos (Santos \& Hoffmann, 2015), mas também ao aumento da satisfação do usuário e, principalmente, pelo envolvimento do cidadão para aprimorar serviços (De Vries et al.,2016). Cumpre destacar que, conforme verificado por Voorberg et al. (2015), ao ser caracterizado como um dos objetivos, o envolvimento do cidadão é assumido como um ganho por si só.

Referente à categoria de análise processo de inovação, observou-se, com base em OECD (2017), como ocorreram as etapas de identificação do problema, geração de ideias, desenvolvimento de propostas, implementação e difusão. Assumiram-se também como referencial os princípios que, segundo Cavalcante (2019), caracterizam processos baseados no design thinking: foco no ser humano, cocriação de soluções e experimentação. Ainda, com base em Voorberg et al. (2015) analisou-se o caráter iterativo e participativo. Para tanto, essa categoria analítica será discutida de forma integrada com as categorias atores envolvidos, abordagem e ferramentas utilizadas.

As etapas de identificação do problema, geração de ideias e desenvolvimento de propostas foram realizadas por meio de uma oficina baseada na abordagem do design thinking, nos moldes do que Trischler e Scott (2016) chamam de workshop de design colaborativo. A oficina teve início com a análise do problema, prosseguiu com atividades para geração de ideias de solução e culminou na definição de um protótipo de solução. Portanto, teve foco nas fases que antecedem a implementação, conforme constatado durante a observação participante.

A oficina realizada na PMBC contou, como atores envolvidos, com dezesseis participantes: seis da prefeitura, sete da sociedade e três de universidades. Dentre os representantes da prefeitura estavam: dois servidores da Secretaria do Meio Ambiente, um efetivo e outro cargo comissionado; dois servidores da Secretaria de Segurança Pública, um efetivo e um estagiário; um servidor comissionado da Secretaria de Turismo; um servidor comissionado do Fundo Municipal de Trânsito; e um servidor admitido em caráter temporário (ACT) da Secretaria de Planejamento. Já entre os representantes da sociedade, estavam: dois representantes de uma entidade do sistema $S$, um representante de uma organização da sociedade civil organizada, e quatro representantes de empresas. Os participantes das universidades foram formados por dois acadêmicos do curso de Administração Pública da Universidade do Estado de Santa Catarina (UDESC) e por um professor da Universidade do Vale do Itajaí (UNIVALI).

As Secretarias da PMBC do Meio Ambiente, Turismo, Segurança Pública e FUMTRAN, envolvidas no serviço em estudo, ficaram livres para escolher o critério de indicação de seus representantes. Para escolher os representantes da sociedade, o E1 aponta que foi realizado um levantamento nos protocolos de pedido de liberação para realização de evento, de usuários que utilizaram mais de uma vez o serviço entre o período de janeiro de 2017 a agosto de 2018. Com esse levantamento, foram contabilizados 32 instituições e cidadãos. Entre estes 32, foi verificado que apenas 22 eram do município de Balneário Camboriú. Esse foi o critério adotado para que os ofícios fossem enviados, convidando-os a participar da oficina.

Referente aos representantes das universidades, foram convidados acadêmicos do curso de Administração Pública do campus da UDESC em Balneário Camboriú, em função da proximidade com o tema da oficina. Da mesma forma, a Universidade do Vale do Itajaí (UNIVALI), localizada no município vizinho, foi convidada a encaminhar representante. Assim, as duas principais universidades da região se fizeram representar, conforme destaca o E2.

Nota-se, portanto, uma composição criteriosa do grupo de participantes da experiência, de forma que diferentes perspectivas pudessem ser trazidas à tona. Além da perspectiva dos servidores da prefeitura, representados por burocratas de nível de rua e de nível médio de diferentes secretarias, 
que seriam tradicionalmente os designers do serviço, ou mesmo dos acadêmicos estudiosos nas técnicas de design, houve o cuidado de incorporar de fato usuários do serviço. Assim, a composição do grupo permitiu ir além do que Lee (2008) chama de designer desenhando o serviço para o usuário, para permitir que o usuário de fato tivesse a oportunidade de fazer parte do processo decisório.

Na perspectiva de Voorberg et al. (2015), o usuário assume a condição de co-designer. Dessa forma, o cidadão deixou de aparecer como causa do problema ou agente que demanda a solução, para ter a oportunidade de fazer parte dela não só como referência para ampliação de entendimento da realidade, mas como participante do processo de construção da solução (Cavalcante, 2019; Jaeger, 2013). Uma composição dessa natureza cria condições para se ir além de uma solução que simplesmente espelha a estrutura e processos vigentes na PMBC, limite frequente quando participam do processo apenas os burocratas, para abrir espaço ao design de respostas inovadoras (Cavalcante, 2019; Ansell \& Torfing, 2014).

Referente à categoria de análise abordagem da inovação na organização, pode-se interpretar que o caso em estudo se aproxima mais da abordagem horizontal (Cavalcante \& Camões, 2017), uma vez que o processo de cocriação ocorreu entre funcionários de baixo e médio escalão, com o envolvimento de líderes, conforme observado pela pesquisadora. Não parece adequado caracterizar a abordagem como top down, pois não foi uma iniciativa que ocorreu no alto escalão. Embora o Prefeito Municipal e os secretários das pastas envolvidas tenham dado o aval para a realização da oficina, a iniciativa não partiu deles. Também não se caracterizou como bottom up, uma vez que gerentes e diretores não apenas participaram da oficina e se comprometeram com a implementação e difusão da solução, como autorizaram seus funcionários a se ausentar das atividades de rotina para participar da experiência.

Como ferramentas para amparar a cocriação nas etapas de identificação do problema, geração de ideias e desenvolvimento de propostas, utilizaram-se a persona, o mapa de empatia, o brainstorming e a prototipagem de serviço. Inicialmente, foram criadas as personas. Elas foram caracterizadas a partir de informações relacionadas a pessoas com perfis semelhantes que solicitam o serviço (Trischler \& Scott, 2016), ou seja, representantes dos cidadãos requerentes que solicitam a liberação para realização de um evento em espaço público. 0 mapa de empatia, construído com base nas personas, proporcionou entendimento acerca das dores e necessidades dos usuários do serviço: melhores informações no protocolo, maior clareza sobre os trâmites internos das solicitações na prefeitura, padronização do formato das solicitações e possibilidade de realização do serviço de forma online. A partir da compreensão dessas necessidades, o brainstorming possibilitou a geração de várias soluções para o problema (Design Council, 2015).

Uma das propostas, que consistiu num formulário padrão que incorporasse todas as informações necessárias segundo declaração de todos os setores da prefeitura envolvidos no processo, foi selecionada de forma unânime. Utilizando post its e canetinhas, os participantes prototiparam o formulário, preocupando-se não apenas com os campos e informações a serem inseridas, mas também com a aparência e interface do documento, para que fosse ele amigável ao usuário. De acordo com o E1, E2, E4, E5, E6, E7 e E8, a prototipagem permitiu comunicar e demonstrar aos participantes como seria esse serviço, submetendo a proposta a teste e refinamento (Stickdorn \& Schneider, 2014).

Assim, o processo teve prosseguimento com a implementação da solução na PMBC. Nessa etapa, duas pessoas emergiram, segundo o entendimento do entrevistado do E2 e a observação da pesquisadora, como tendo desempenhado papel-chave: uma funcionária da Secretaria do Planejamento e uma da Secretaria do Meio Ambiente. Ambas ficaram responsáveis pela implementação, monitoramento, acompanhamento e alterações, quando necessárias, bem como pela difusão da inovação na organização.

Seguindo os princípios de iteração, captura de feedback, aprendizagem e adaptação propostos pelo design, ambas as Secretarias monitoraram por um mês o uso do formulário, e foram realizados ajustes quando necessários, conforme aponta o E9. Nessa etapa, o E9 destaca que os usuários que participaram da oficina auxiliaram com feedback constante na medida em que iam utilizando o serviço no novo formato. Como visto em Bressers (2014), existe uma modificação na intensidade e forma de participação do usuário nessa fase. Enquanto na etapa de design da solução ela foi mais intensa e direta, na implementação tem como foco o follow up necessário para garantir o alinhamento. Assim, nota-se que houve, no processo, o movimento iterativo proposto pelo design thinking, principalmente na etapa inicial da implementação, em que o protótipo foi sujeito a período de teste e captura sistemática de feedback até que atingisse seu formato final.

Finalmente, no último estágio do processo, ocorreu a difusão. De acordo com o E9, com o formulário já testado e aceito pelos usuários e pelos servidores das diferentes secretarias, ele passou a ser difundido na organização. A Secretaria de Planejamento incumbiu se de comunicar a adoção do 
novo formulário aos demais setores da Prefeitura. Assim, observa-se a consecução do processo da inovação que, segundo Schumpeter (1984), requer a implementação e difusão do novo.

As entrevistas realizadas com o E1, E2 e E3 sugerem que a participação das secretarias envolvidas no serviço, na etapa inicial que culminou na invenção, gerou um sentimento de pertencimento que mitigou resistência ao novo, facilitando a implementação e a difusão. Chega-se, assim, às categorias de análise indutores e barreiras. Os indutores que facilitaram o processo e a consecução da inovação foram, segundo os entrevistados: o método utilizado na oficina; a liderança; a multidisciplinaridade, proporcionada pela participação de representantes de diversas secretarias; e a parceria entre o poder público e os usuários do serviço. Tais fatores dialogam com indutores destacados na literatura (European Comission, 2013; Puttick, Baeck \& Colligan, 2014). Ainda, o E1, E2, e E3 destacam como indutor a má comunicação que existia anteriormente entre as secretarias, que os motivou para a busca de uma solução. De forma similar, pode-se destacar como indutor externo a expectativa, por parte dos usuários, de resolver o problema (European Comission, 2013), conforme destacado pelo E1, E6 e E7. Cabe apontar nessa categoria de análise, ainda, a cooperação entre a Secretaria de Meio Ambiente e de Planejamento, reconhecidas pelos E1, E2 e E3 como líderes no processo, bem como o engajamento conseguido por parte de todos os atores envolvidos (Demircioglu \& Audretsch, 2017).

Como barreiras, o E1, E2 e E3, de um modo geral, apontaram a descontinuidade das equipes e dos projetos exitosos, devido à alternância do poder na gestão pública e a resistência à mudança. Além desses, os servidores entrevistados mencionaram a ausência de práticas de fomento à inovação na prefeitura, a tendência à acomodação e manutenção das rotinas e, por último, a falta de política corporativa de estímulo à inovação (Resende Junior, Guimarães \& Bilhim, 2013; Koch et al., 2006). Ao trazer à tona a resistência à mudança, os entrevistados reforçam novamente o papel da liderança que emergiu no processo para motivar os servidores a saírem da sua zona de conforto e participarem de uma nova tentativa, visto que antes dessa experiência, outras duas reuniões internas haviam sido realizadas com foco no mesmo problema, mas sem sucesso.

Por fim, o modelo de análise adotado nesta pesquisa propôs caracterizar o tipo de inovação resultante da experiência e os resultados alcançados. Quanto ao tipo, pode-se considerar que a experiência gerou uma inovação em serviço e incremental (Walker, Damanpour \& Devece, 2010), uma vez que foi aprimorado parte de um serviço já existente. Além disso, as melhorias respeitaram as características ou finalidade dos serviços originais, o que é típico do tipo de inovação que o OPSI (2018) classifica como inovação orientada ao aprimoramento. Ainda na perspectiva do OPSI, tem-se também características de inovação adaptativa, na medida em que se procura mudar algo que não está acontecendo da forma esperada. Na intersecção entre a inovação orientada ao aprimoramento e a inovação adaptativa, embora não haja um desafio ao status quo, tende-se a ter ganhos de eficiência e de efetividade, uma vez que se constrói sobre o aprendizado corrente acerca do que funciona e não funciona, diminuindo a lacuna entre o que se deseja ter e o que se tem. Nesse sentido, trata-se de um tipo de inovação que atende aos objetivos estabelecidos pelas partes envolvidas no caso, conforme visto anteriormente.

Pode-se atribuir à inovação resultante da experiência estudada como uma inovação frugal, uma vez que se gerou valor atraente ao público-alvo por meio de uma solução com baixo grau de sofisticação, uso de poucos recursos, mas foco nas funcionalidades essenciais, por meio de um esforço de improvisação criativa (Koerich \& Cancellier, 2019).

Não obstante, com base em Hartley (2005), pode-se remeter a características de uma inovação em governança. Nesse sentido, a inovação se caracteriza por ter acontecido em um nível local, na municipalidade, com o objetivo de melhorar o serviço de linha de frente e onde os representantes da sociedade participaram como co-designer (Voorberg et al., 2015). Ao ultrapassar as fronteiras, a PMBC pôde encontrar recursos adicionais, materializados no conhecimento dos participantes externos, maior capacidade operacional e mais legitimidade (Hartley, 2005).

Na medida em que se tratou de uma iniciativa pioneira no que tange o uso do ferramental do design thinking para apoio à solução de problemas, pode-se considerar que a experiência constituiu uma inovação organizacional para a PMBC (OECD, 2005). Observa-se assim que, conforme explicam Walker et al. (2010), uma inovação não se limita a uma classificação em particular, podendo haver combinações entre diferentes tipologias.

Referente aos resultados adquiridos com a implementação da solução, ou seja, com a inovação realizada na PMBC, pode-se iniciar destacando o fato de o formulário ter sido colocado em uso e a funcionalidade que ele trouxe para o serviço. Isso representou o atingimento do objetivo da experiência segundo os entrevistados. Importante também destacar o reconhecimento, tanto pelo E1, E2 e E3, quanto pelo E4, E5 e E6, dos ganhos obtidos. Os entrevistados apontaram que as informações necessárias para a autorização de um evento em espaço público se tornaram bem definidas. Os 
usuários têm clareza das informações e documentos necessários para dar entrada em um pedido, compreendem a tramitação interna na prefeitura, percebem agilidade na autorização e compreendem as situações em que os pedidos não são aprovados, conforme aponta o E4, E5 e o E6. Na percepção do E1, E2 e E3, as informações e documentos necessários se tornaram claros, há entendimento da análise feita por cada secretaria envolvida e, consequentemente, ganhou-se eficiência na análise.

Assim, estão presentes no caso estudado resultados esperados de inovações no setor público elencados por De Vries et al. (2016), a saber: eficiência em ações internas e aprimoramento de serviços e soluções para cidadãos. Os resultados encontrados também dialogam com a literatura que aborda a participação social de forma mais ampla: possibilita novas formas de governança; confere maior transparência e legitimidade às decisões públicas; melhora a qualidade da tomada de decisão, a partir do conhecimento e experiência dos cidadãos; traz maior eficácia, agilidade e economia às ações públicas; propicia soluções inovadoras e novas formas de entrega dos serviços públicos (Struecker \& Hoffmann, 2017). A pesquisa evidenciou também o alcance de resultados esperados segundo a literatura que trata especificamente da cocriação, maior efetividade, eficiência e satisfação do usuário (Voorberg et al., 2015).

\section{Considerações Finais}

Este trabalho analisou uma experiência de cocriação para a inovação de um serviço público no contexto de uma prefeitura. Com base em lacunas de conhecimento apontadas por Voorberg et al. (2015), Trischler \& Scott (2016) e Cavalcante (2019), procurou-se sistematizar evidências que possam contribuir para um entendimento mais profundo sobre a cocriação e o uso de princípios associados ao design thinking como estratégias relevantes para a inovação no serviço público, bem como sobre como eles podem ser incorporadas nas práticas da administração pública. Nesse sentido, o artigo traz contribuições teóricas para a literatura, assim como elementos com potenciais implicações gerenciais.

A análise dos dados coletados revelou uma experiência que permitiu uma definição mais precisa do problema público que a originou e o design de uma solução que proporcionou ganhos em eficiência e legitimidade para a administração pública e a melhoria da qualidade do serviço para o usuário. A pesquisa sugere que isso foi possível graças a um conjunto de fatores que tem no centro a composição criteriosa de um grupo de atores o qual, de fato, desenvolveu um processo iterativo de colaboração, desde a análise do problema até a implementação da solução. 0 usuário fez parte do processo decisório (Lee, 2008), assumindo a condição de co-designer (Voorberg et al., 2015). Ele deixou de ser assumido como a causa do problema ou agente que demanda a solução, para fazer parte dela (Cavalcante, 2019; Jaeger, 2013).

A ausência da figura da alta gestão como sponsor da iniciativa sugere a importância do médio e baixo escalão da burocracia em experiências de cocriação. A liderança emergente no processo configurou um impulsionador de destaque e permitiu a caracterização de uma abordagem horizontal na inovação estudada.

A inovação resultante da experiência revelou características de inovação frugal. 0 processo que se estabeleceu permitiu gerar valor atraente ao usuário por meio de uma solução de baixa sofisticação, uso de poucos recursos e foco nas funcionalidades essenciais. Koerich e Cancellier (2019) associam a inovação frugal a um esforço de improvisação criativa e, nesse sentido, novos estudos relacionando esse tema ao uso de princípios do design thinking para a cocriação de serviços podem ser sugeridos.

0 trabalho também aponta conexões com a literatura que discute inovação em governança. Ao ultrapassar suas fronteiras para a solução de um problema, a PMBC pôde encontrar recursos adicionais, materializados no conhecimento dos participantes externos (usuários do serviço), maior capacidade operacional e mais legitimidade (Hartley, 2005).

A compatibilidade entre os objetivos que motivaram a experiência e os resultados alcançados sugere a presença de elementos capazes de contribuir para a evolução das abordagens tradicionais de solução de problemas públicos. Entretanto, ao concentrar-se no estudo de uma experiência em particular, o presente trabalho apresenta limites. Mais evidências são necessárias para que se possa compreender de maneira profunda como o design thinking pode facilitar processos de cocriação e como esta pode contribuir para a promoção de inovações no serviço público.

Além das sugestões de trabalhos futuros já apresentadas, com base nessa pesquisa, pode-se também sugerir estudos orientados a melhor compreender como experiências bem sucedidas podem ser replicadas em uma organização. No caso estudado, o fomento ao processo ficou centrado na figura do líder, servidor de nível médio na hierarquia da prefeitura, que não conseguiu dar andamento em outras iniciativas, permitindo replicar o aprendizado obtido. 


\section{Agradecimentos}

As autoras agradecem à Fundação de Amparo à Pesquisa e Inovação do Estado de Santa Catarina (FAPESC) pelo apoio recebido para o desenvolvimento da pesquisa.

\section{Referências}

Ansell, C., \& Torfing, J. (2014). Collaboration and design: new tools for public innovation. In C. Ansell, \& J. Torfing. Public Innovation through collaboration and design. New York: Routledge.

Bardin, L. (2006). Análise de conteúdo. Lisboa: Edições 70.

Brandsen, T., \& Honingh, M. (2015). Distinguishing different Types of coproduction: a conceptual analysis based on the classical definitions. Public Administration Review. 76 (3), 427-435.

Bressers, N. (2014). The impact of collaboration on innovative projects: a study of Dutch water management. In C. Ansell \& J. Torfing (Orgs.). Public innovation through collaboration and design. New York: Routledge.

Cavalcante, P. (2019). Inovação e políticas públicas: superando o mito da ideia. Brasília: IPEA.

Cavalcante, P., \& Camões, M. (2017). Inovação pública no Brasil: uma visão geral de seus tipos, resultados e indutores. In P. Cavalcante et al (Orgs.). Inovação no setor público: teoria, tendências e casos no Brasil. Brasília: Enap Ipea.

De Vries, H. A., Bekkers, V., \& Tummers, L. G. (2016). Innovation in the Public Sector: A systematic review and future research agenda. Public Administration, 94 (1), 146-166.

Demircioglu, M. A., \& Audretsch, D. B. (2017). Conditions for innovation in public sector organizations. Research Policy, 46 (9), 1681-1691.

Design Council (2015). Design methods for developing services. Recuperado em 03 de dezembro, 2019, de https://www.designcouncil.org.uk/sites/default/files/asset/document/ DesignCouncil_Design\% 20methods\%20for\%20developing\%20services.pdf

European Comission (2013). Powering European Public Sector Innovation: Towards a New Architecture. Report of the Expert Group on Public Sector Innovation, Directorate General for Research and Innovation, Innovation Union, European Commission, Brussels.

Hartley, J. (2005). Innovation in Governance and Public Services: Past and Present. Public Money and Management, 25 (1), 27-34.

Jaeger, B. (2013). User involvement in public sector innovation. In S. P Osborne, \& L. Brown. Handbook of innovation in public services. Cheltenham: Edward Elgar.

Koch, P., Cunningham, P., Schwabsky, N., \& Hauknes, J. (2006). Summary and policy recommendations. Oslo: Publin.

Koerich, G. V., \& Cancellier, É. L. P. (2019). Inovação Frugal: origens, evolução e perspectivas futuras. Cadernos EBAPE. BR, 17 (4), 1079-1093.

Lee, Y. (2008). Design participation tactics: the challenges and new roles for designers in the co-design process. Co Design, 4(1), 31-50.

Lochhead, H. (2017). Resilience by design: can innovative process deliver more?. Procedia Engineering, $180,7-15$.

Observatory of Public Sector Innovation (2018). Public Sector Innovation Facets. Recuperado em 09 de maio, 2020, de https://oecd-opsi.org/projects/innovation-facets/

Organisation for Economic Co-operation and Development (2005). Oslo manual: guidelines for collecting and interpreting innovation data (3a ed.). Paris: OECD.

Organisation for Economic Co-operation and Development (2017). What's possible? Finding and filtering innovative ideas. Paris: OECD.

Osborne, S. P. (2013). A service-influenced approach to public service innovation. In S. P. Osborne, \& L. Brown. Handbook of innovation in public services.Cheltenham: Edward Elgar.

Puttick, R., Baeck, P., \& Colligan, P. (2014). The teams and funds making innovation happen in governments around the world. Londres: Nesta \& Bloomberg.

Resende Junior, P., Guimarães, T. A., \& Bilhim, J. (2013). Inovação no setor público: análise comparativa entre organizações do Brasil e Portugal. Revista Portuguesa e Brasileira de Gestão, 12 (4), 02-11.

Rittel, H. W., \& Webber, M. M. (1973). Dilemmas in a general theory of planning. Policy sciences, 4 (2), 155-169.

Santos, G. F. Z., \& Hoffmann, M. G. (2015). Em busca da efetividade na administração pública: proposição de uma metodologia para design e implementação de serviços públicos no município de Florianópolis. Navus - Revista de Gestão e Tecnologia, 6, 88-105.

Schuch, E. M.; Souza, V. B. \& Salm, V. M. (2019). As características da coprodução dos serviços públicos a partir da aplicação do Design Thinking em um serviço público da Prefeitura Municipal de Balneário Camboriú. Anais VI Encontro Brasileiro de Administração Pública, Salvador, 6, 1-16.

Schumpeter, J. A. (1982). Teoria do desenvolvimento econômico. São Paulo: Abril Cultural. 
Stickdorn, M., \& Schneider, J. (2014). Isto é Design Thinking de Serviços: fundamentos - ferramentas casos. Porto Alegre: Bookman.

Struecker, D. R., \& Hoffmann, M. G. (2017). Participação social nos serviços públicos: caracterização do estado da arte por meio de bibliometria e revisão sistemática. Revista de Gestão, 24 (4), 371-380.

Trischler, J., \& Scott, D. R. (2016). Designing public services. The usefulness of three service design methods for identifying user experience. Public Management Review, 18 (5), 718-739.

Vergara, S. C. (2011). Projetos e relatórios de pesquisa em administração (13a ed.). São Paulo: Atlas.

Voorberg, W, H., Bekkers, V. J. J. M., \& Tummers, L. G. (2015). A systematic review of co- creation and coproduction: embarking on the social innovation journey. Public Management Review, 17(9), 1333-1357.

Walker, R. M., Damanpour, F., \& Devece, C. (2010). Management innovation and organizational performance: the mediating effect of performance management. Journal of Public Administration Research and Theory, 21(2), 367-386.

Zappellini, M. B., \& Feuerschütte, S. G. (2015). 0 uso da triangulação na pesquisa científica brasileira em administração. Administração: Ensino \& Pesquisa, 16 (2), 241-273. 